\title{
Efficient Facilitated Transport of Lead and Cadmium across a Plasticized Triacetate Membrane Mediated by D2EHPA and TOPO
}

\author{
Omar Arous $^{1,2^{*}}$, Fairouz Saad Saoud ${ }^{1}$, Mourad Amara ${ }^{1,2}$, Hacène Kerdjoudj ${ }^{1}$ \\ ${ }^{1}$ Laboratory of Hydrometallurgy and Inorganic Molecular Chemistry, Faculty of Chemistry, University of Sciences and Technology \\ Houari Boumediene, Bab Ezzouar, Algeria; ${ }^{2}$ Center of Research in Physical and Chemical Analysis, Algiers, Algeria. \\ Email: omararous@yahoo.fr
}

Received February $9^{\text {th }}, 2011$; revised March 11 ${ }^{\text {th }}, 2011$; accepted April 21 ${ }^{\text {st }}, 2011$.

\begin{abstract}
Cellulose triacetate membranes doped with organo-phosphoric carriers (2-ethylhexyl) phosphoric acid noted (D2EHPA) or trioctyl phosphine oxide noted (TOPO) as fixed carriers and 2-nitro phenyl octyl ether noted (NPOE) or tris ethylhexyl phosphate noted (TEHP) as a plasticizers have been prepared and applied for investigation to the facilitated transport of $\mathrm{Pb}(I I)$ and $\mathrm{Cd}(\mathrm{II})$ ions from aqueous nitrate source phase. The membranes Polymer - Plasticizer - Carrier were characterised using chemical techniques as well as Fourier Transform Infra-Red (FTIR), X-ray Diffraction and Scanning electron microscopy (SEM). A study of the transport across a polymer inclusion membrane has shown that the lead or cadmium transport efficiency was increased using D2EHPA as carrier at pH 1-2.
\end{abstract}

Keywords: Cellulose Triacetate, NPOE, TEHP, D2EHPA, TOPO, Membrane

\section{Introduction}

Liquid membranes have received considerable attention by many researchers because of their high selectivity accomplished by carriers incorporated in the membranes. Many efforts have been done to investigate the use of liquid membranes for various separation and purification processes such as separation of isomers [1,2], gases [3-5], metal ions [6,7], etc.

The separation and removal of toxic metal cations and neutral chemicals from water has frequently been addressed in membrane separation systems. Environmentally damaging and toxic anions have received significantly less attention primarily due to the challenging nature of selectively binding anions. Recently, a novel type of liquid membrane called polymer inclusion membrane (PIM) has been developed which provides metal ion transport with high selectivity, as well as easy setup and operation [8]. Polymer inclusion membranes (PIM) show great potential for industrial separations over other membrane types. Bulk liquid membranes (BLM) are not economically scalable to industrial levels, while the more practical supported liquid membranes (SLM) tend to lose solvent to the water phases. PIM consist of a polymer support, which is commonly cellulose triacetate (CTA), a plasticizer (solvent) and carrier molecules. The plasticizer is an integral part of the membrane, acting as the solvent in which the carrier diffuses. This makes the membrane easy to handle and promotes membrane durability. In fact, the common plasticizer $o$-nitrophenyl octyl ether (NPOE) suffers virtually no loss from the membrane into adjacent water phases [9]. Also, PIM demonstrate permeability of ionic and neutral species comparable to SLM [10]. Any loss of transport in PIM in comparison to SLM is due to slower diffusion across the membrane, however, the higher carrier capacity of CTA membranes helps increase transport to counteract this effect $[11,12]$. The PIM plasticizer can be changed to optimize transport. NPOE, TEHP are common plasticizers in CTA-based PIM. The durability and relatively high polarity of NPOE allow counter ions to be dissolved in the membrane as free ions. NPOE has the further advantages that it is non-volatile, high boiling and insoluble in water. CTA-based PIM using NPOE as the plasticizer retain macrocyclic carriers, such as calixarenes and provide a stable, durable membrane [13-17]. The fabrication and characterization of new membranes is reported recently $[18,19]$.

Facilitated transport of metal ions through PIM carrier 
membranes has resulted in good selectivity in ions separations with real improvements of the membrane stability as compared to liquid membranes as well as polymer stabilized liquid membranes. This is reflected by an increasing number of PIM investigations reported in the literature over the last two decades [20,21]. Transport studies through cellulose triacetate membranes as polymeric matrix with showing high flux and good stability have been recently reported [22-34].

In this work, we have developed a novel class of plasticized cellulose triacetate membranes modified by organo-phosphoric carrier's incorporation that are selectively permeable to lead and cadmium cations. The membrane CTA - Plasticizer - Carrier was characterised using chemical techniques as well as Fourier Transform Infra Red (FTIR), X-Ray Diffraction, and Scanning electron microscopy (SEM). We compared the behaviour of a Di (2-ethylhexyl) Phosphoric acid noted $\mathrm{D}_{2}$ EHPA (Acid-type carrier) and a Trioctylphosphine oxide noted TOPO (solvating-type carrier) towards a facilitated transport of lead and cadmium through a synthesized membrane.

\section{Experimental}

\subsection{Reagents}

Analytical-grade inorganic chemicals: $\mathrm{Pb}\left(\mathrm{NO}_{3}\right)_{2}, \mathrm{Cd}\left(\mathrm{NO}_{3}\right)_{2}$, were obtained from CARLO ERBA. Organic reagents: cellulose triacetate (CTA), o-nitrophenyl octyl ether (NPOE), chloroform were purchased from Fluka. Tris ethylhexyl phosphate (TEHP) was purchased from Merck. The ion carriers (2-ethylhexyl) phosphoric acid (D2EHPA) and trioctyl phosphine oxide (TOPO) were obtained from Aldrich. Doubly distilled water was used for preparing all aqueous solutions.

\subsection{Membrane Preparation}

Polymer Inclusion Membranes were prepared using the same procedure described by Sugiura et al. [34]. The solution of cellulose triacetate $(0.2 \mathrm{~g})$ (Figure 1), ion carrier (D2EHPA or TOPO) (Figure 2), and plasticizer (o-nitrophenyl octyl ether) or tris ethylhexyl phosphate $(0.2 \mathrm{~mL})$ (Figure 3) in chloroform $(20 \mathrm{~mL})$ was poured into a Petri glass of $9.0 \mathrm{~cm}$ diameter. The solvent was allowed to evaporate overnight and the resulting membrane was separated from the Petri glass by immersion in cold water.

\subsection{Transport Studies}

Transport experiments were carried out in a permeation cell in which the membrane film was tightly clamped between two cell compartments. Both the source and receiving aqueous phases $(50 \mathrm{~mL}$ each) were stirred at

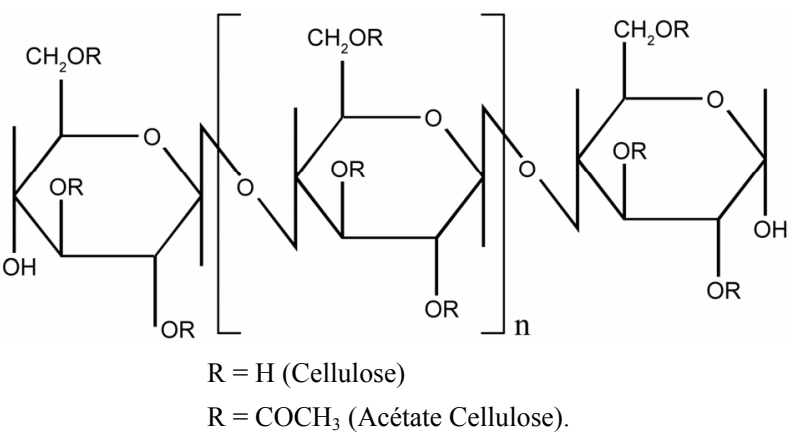

Figure 1. Cellulose triacetate polymer.<smiles>CCC(COP(=O)(O)OCC(c1ccccc1)c1ccccc1)c1ccccc1</smiles>

(D2EHPA)<smiles>O=P([16OH])([165I])c1ccccc1</smiles>

(TOPO)
Figure 2. Organo-phosphoric carriers.

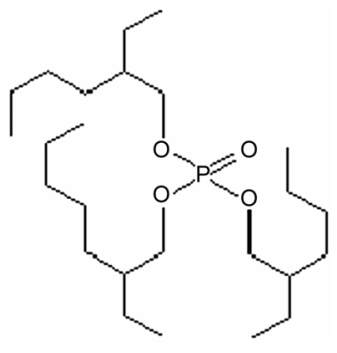

(TEHP)<smiles>COCCOc1ccccc1[N+](=O)OC</smiles>

(NPOE)
Figure 3. Plasticizers used in the PIM.

$800 \mathrm{rpm}$. Samples of the aqueous receiving phase were removed periodically via a sampling port with a syringe and after appropriate dilution with deionized water were analyzed to determine the metal ion concentrations by the Atomic Absorption Spectroscopy technique (AAS). Three independent experiments were realized to determine the lead and cadmium concentration. The experimental standard deviation was determined to be $\pm 5 \%$.

Transport of lead and cadmium ions obeys to a facilitated co-transport in the case of TOPO (solvating-type carrier) and counter-transport in the case of D2EHPA (Acid-type carrier).

The mechanism transport is represented in Figures 4(a) and 4(b). The metal ion is complexed at the interface feed-phase/membrane and the complex formed diffuses through the membrane phase to the interface membrane/ strip-phase where the decomplexation of the metal ion is realized [35]. The mass flux can be calculated by the 
equation $J=\frac{\Delta n}{S \Delta t}$ where $\Delta n$ is the variation of the number of moles in the feed phase during the interval time $\Delta t(s)$ and $S$ is the membrane area $\left(\mathrm{cm}^{2}\right)$.

\subsection{Analyses}

The metal concentrations were determined by samplings at different time intervals aliquots of $0.5 \mathrm{ml}$ each from the feed and strip solutions and analysed with an atomic absorption spectrophotometer (Perkin Elmer 2380). Mass flux $J\left(\mathrm{~mol} \cdot \mathrm{cm}^{2} \cdot \mathrm{s}^{-1}\right)$ of the metal ions through the PIM transferred from the feed side of the membrane to the strip side was determined applying its definition: $J=$ $\Delta n / S \Delta t$, where $\Delta n$ represents the variation in mole number of metal ions in the receiving solution during the reference time $\Delta t$, and $S$ is the membrane active area. IR spectra were recorded on with Perkin Elmer spectrophotometer (Spectrum one). X-ray analyses were recorded on a Bruker D8 Advance AXS diffractometer.

\section{Results and Discussion}

\subsection{Physical and Chemical Characteristics of Cellulose Triacetate Membranes}

In Table 1, some of the characteristics of the membrane made with the carriers have been listed in comparison with those of the reference CTA membrane. As the carrier

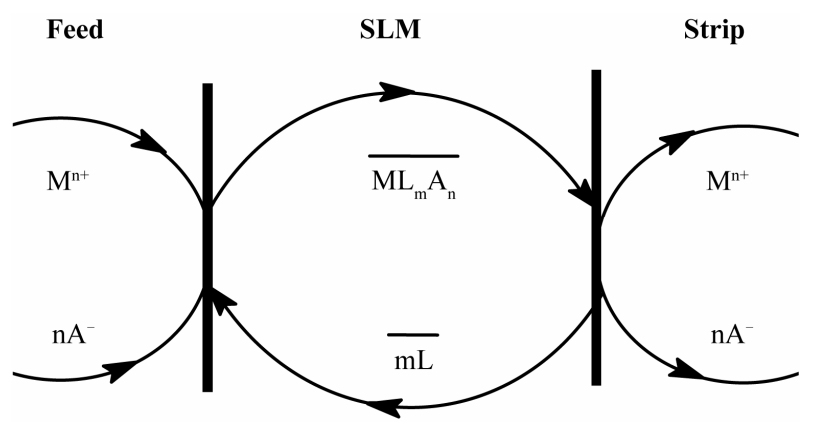

(a)

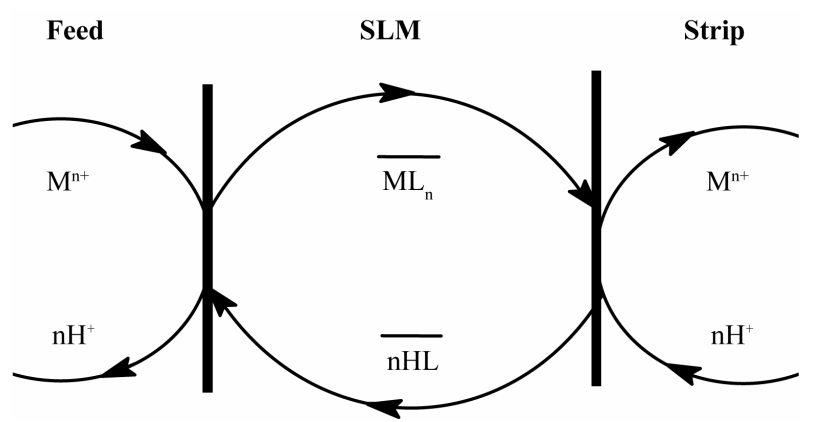

(b)

Figure 4. (a) Facilitated co-transport; (b) Facilitated countertransport mechanisms.
Table 1. Chemical and physical characteristics of cellulose triacetate membranes.

\begin{tabular}{lccc}
\hline \multicolumn{1}{c}{ membrane } & $\begin{array}{c}\text { thickness } \\
(\mu \mathrm{m})\end{array}$ & $\begin{array}{c}\text { density } \\
\left(\mathrm{mg} / \mathrm{cm}^{2}\right)\end{array}$ & contact angle $\left(^{\circ}\right)$ \\
\hline CTA & 10 & 4.88 & 46.4 \\
CTA-NPOE & 15 & 6.12 & 80.5 \\
CTA-TEHP & 12 & 5.84 & 75.8 \\
CTA-NPOE-TOPO & 32 & 7.42 & 79.2 \\
CTA-TEHP-TOPO & 28 & 6.91 & 76.3 \\
CTA-NPOE-D2EHPA & 27 & 6.87 & 78.8 \\
CTA-TEHP-D2EHPA & 25 & 6.33 & 76.1 \\
\hline
\end{tabular}

molecules (TOPO and D2EHPA) and plasticizers (NPOE and TEHP) are hydrophobic, the location of carrier molecules at the surface of the CTA modified membranes should modify the contact angle which is a parameter indicative of the wetting character of a material.

\subsection{Ray Diffraction}

Figures 5 (a-d) show the $\mathrm{X}$ - ray curves for cellulose triacetate $(\mathrm{CTA})+$ plasticizers + carriers membranes.

Based on this figure, we can observe the following:

- The CTA membrane presents a single maximum located at approximately $20^{\circ}$ found in all polymers and corresponds to the Van der Waals halo [36,37]. Thus, this material presents basically amorphous characteristics.

- The systems constituted by the mixture of CTA + $\mathrm{NPOE}+$ carrier and CTA + TEHP + carrier do not give any diffraction. It can be due to the absence of crystallisation within the membrane which permits us to eliminate the mechanism of transfer of the ions by successive jumps between carrier complexing sites in a 3D assembled state.

\subsection{Characterization by FTIR}

The membranes CTA + Plasticizer + Carrier were characterised using chemical techniques as well as Fourier Transform Infra - Red (FTIR). IR spectra were recorded on with Perkin - Elmer (Spectrum One) spectrophotometer.

Figures 6 and 7 show the spectrums of the different membranes synthesised.

Table 2 collects the peak values and the corresponding radical of the reference CTA, TEHP, NPOE, CTA + TEHP and CTA + NPOE membranes.

The obtained results showed that all the maximum values extracted from the spectrum of the CTA reference membrane, i.e. without plasticizer and carrier, are present 


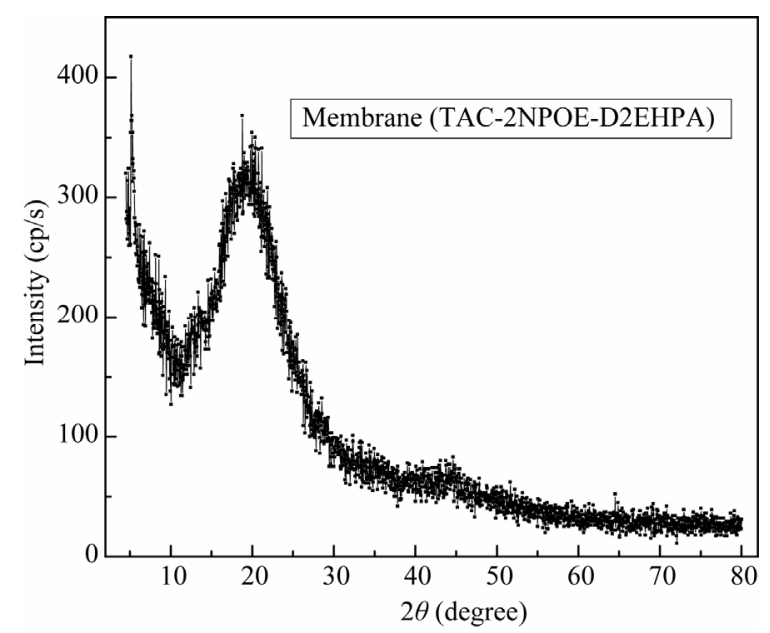

(a)

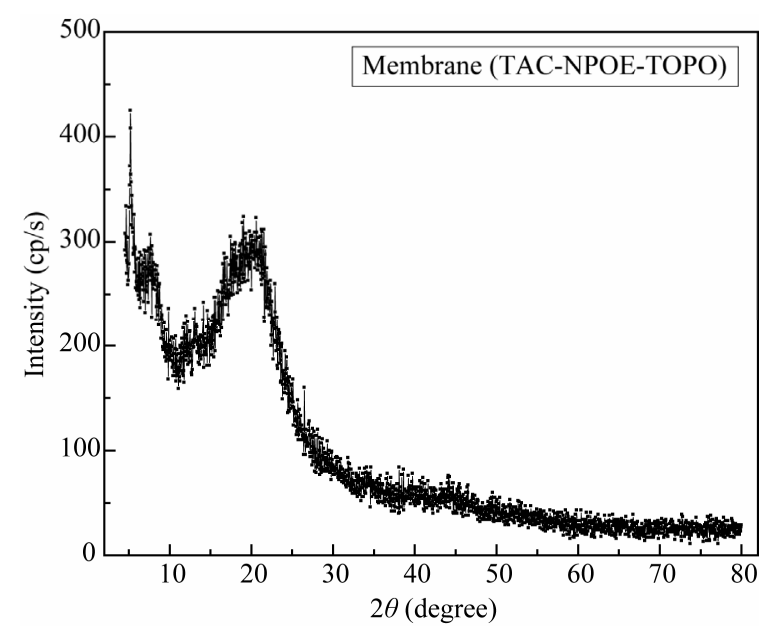

(c)

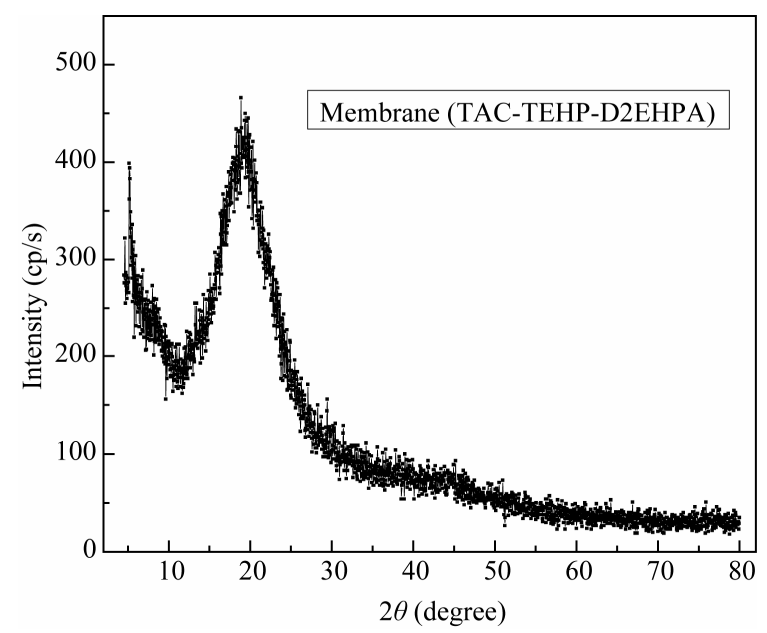

(b)

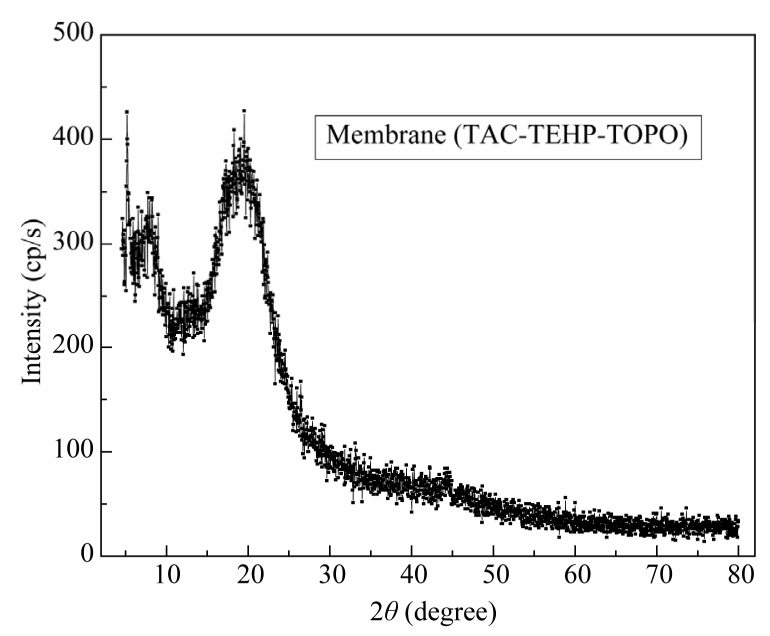

(d)

Figure 5. X-ray curves for (CTA + NPOE + D2EHPA), (CTA + TEHP + D2EHPA), (CTA + NPOE + TOPO) and (CTA + NPOE + TOPO) membranes.

in the modified membranes spectra in addition to those of the carrier molecules. This result confirms the presence of plasticizer and carrier in the polymer matrix.

\subsection{Characterisation by Scanning Electron Microscopy (SEM)}

The morphologies of the CTA + Plasticizer + carrier membranes (cross section) (Figure 8) show that the CTA-plasticizer (NPOE or TEHP) and carrier (TOPO or D2EHPA) membranes present a dense structure where the pores of membrane have been filled by the NPOE, TEHP TOPO and D2EHPA molecules yielding a thick and less porous membrane.

\subsection{Influence of the Plasticizer Nature}

We examined the effect of a plasticizer nature. We used two plasticizers (NPOE and TEHP).

Figure 9 shows the concentrations of lead in a strip phase using TOPO as carrier and two plasticizers. It can be perceived that tris (2-etheylhexyl) phosphate (TEHP, viscosity, $\eta=10.2 \mathrm{cP}$, dielectric constant, $\varepsilon r=4.8)$ and 2-nitrophenyl octyl ether (NPOE, $\eta=12.8 \mathrm{cP}, \varepsilon r=23.1$ ) produces the highest PIM transport of ions.

\subsection{Influence of the Carrier Nature}

The transport has been achieved with two carriers (TOPO and D2EHPA) using a same polymer and a same plasticizer (NPOE).

Figure 10 represents the variation of the concentration of lead ions in the strip phase versus time using TOPO and $\mathrm{D}_{2}$ EHPA carriers. The results show that the concentration of lead in the strip phase obtained with $\mathrm{D}_{2}$ EHPA 


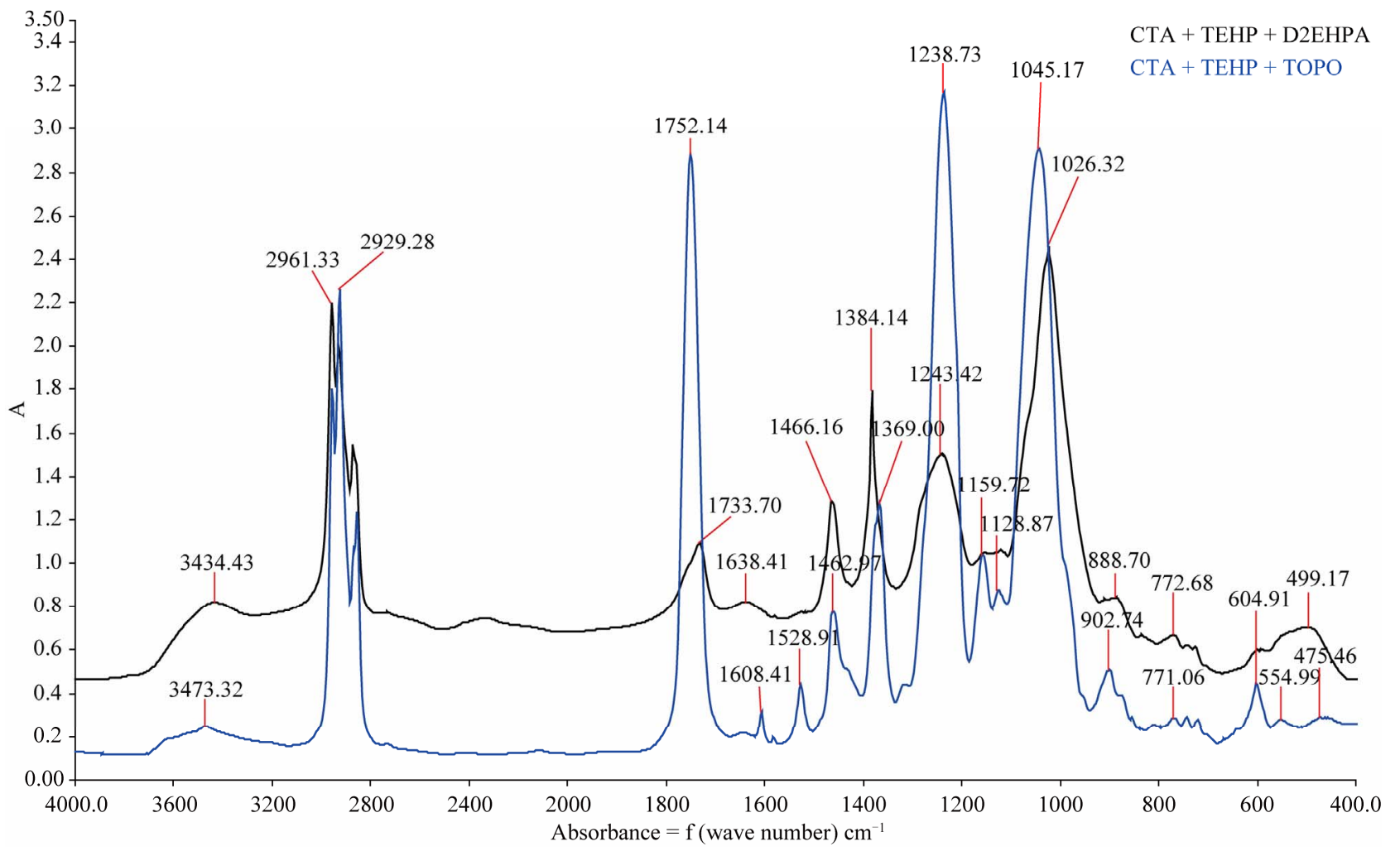

Figure 6. FTIR spectrums of the CTA + TEHP + carriers membranes.

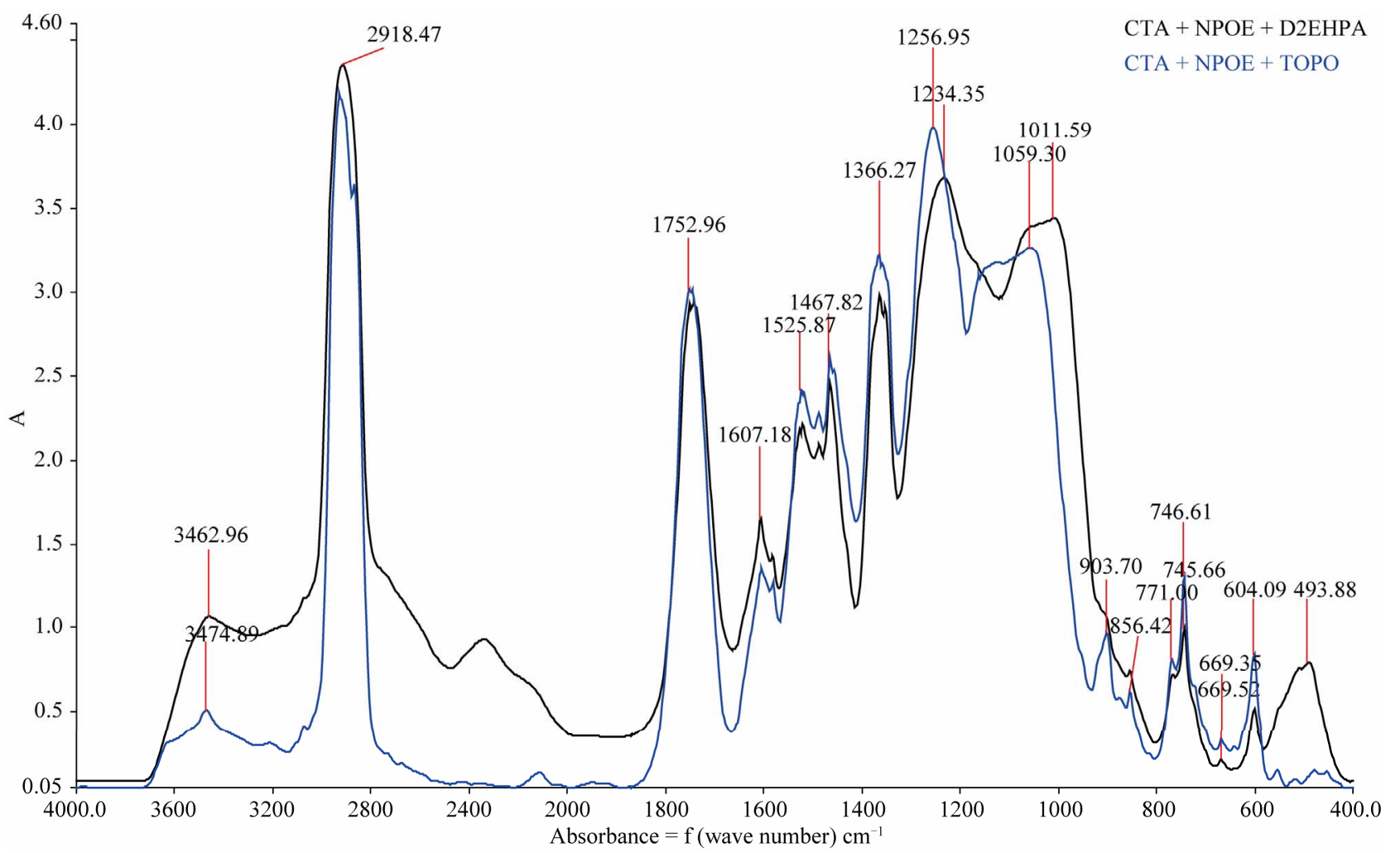

Figure 7. FTIR spectrums of the CTA + NPOE + carriers membranes. 


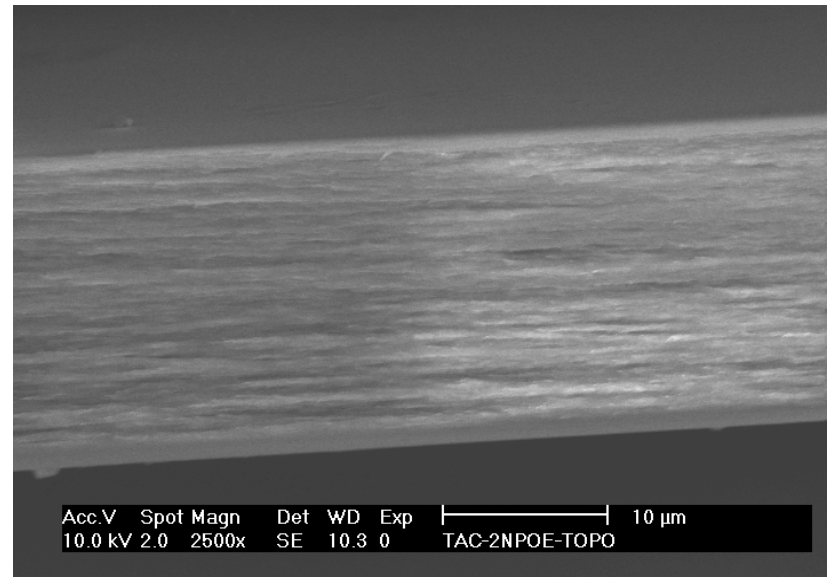

$\mathrm{CTA}+\mathrm{NPOE}+\mathrm{TOPO}$ (Cross-section)

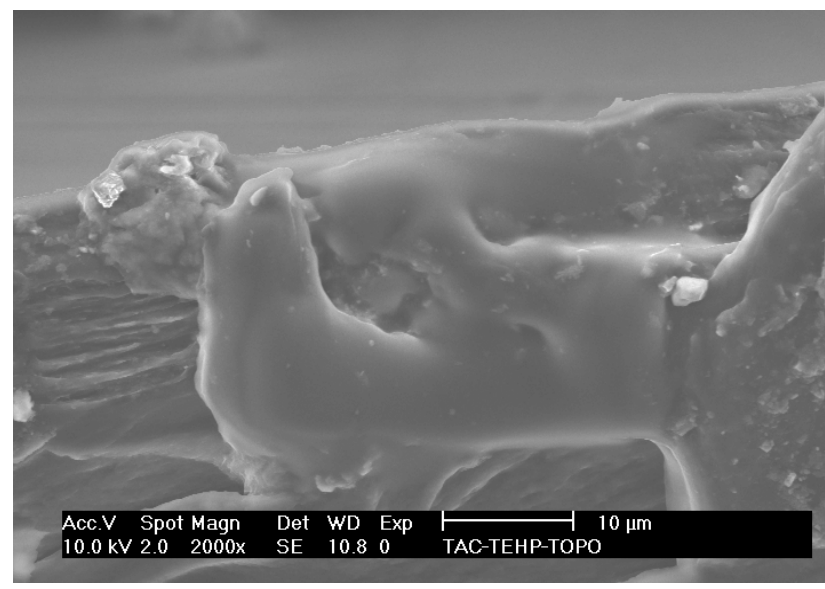

CTA + TEHP + TOPO (Cross-section)

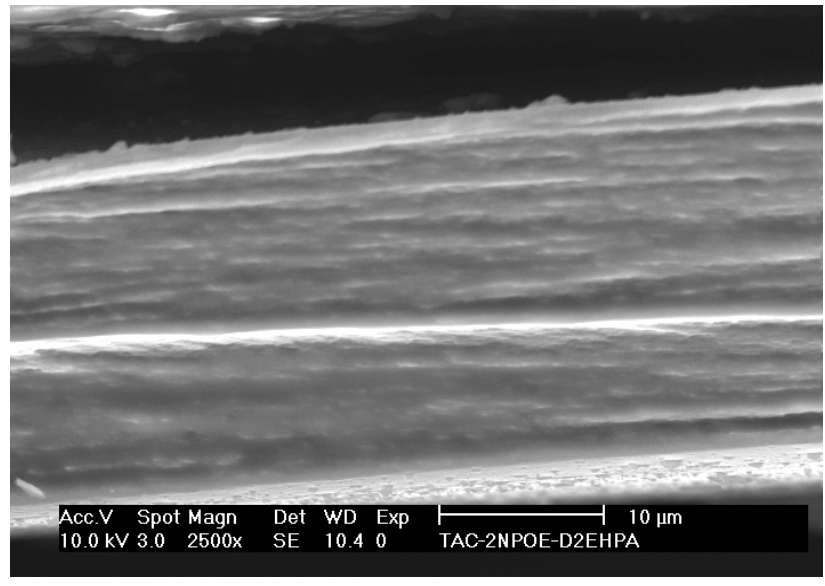

$\mathrm{CTA}+\mathrm{NPOE}+\mathrm{D} 2 \mathrm{EHPA}$ (Cross-section)

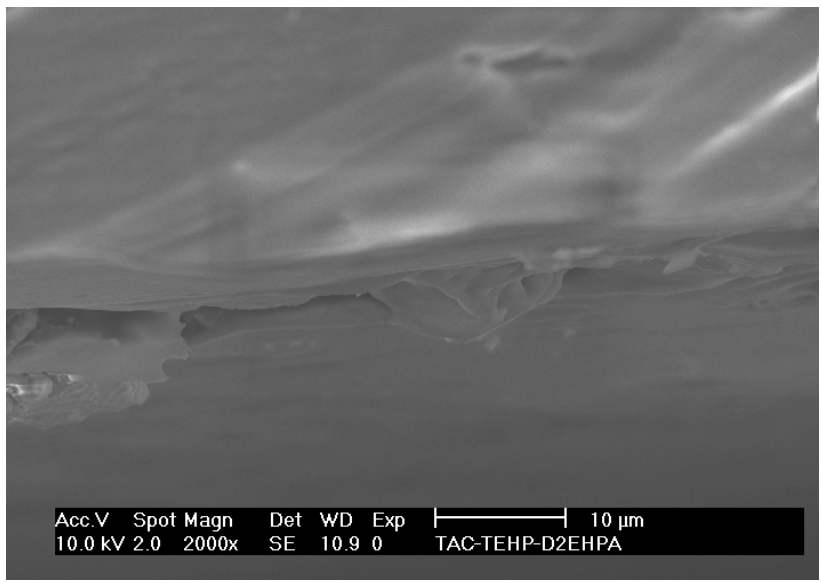

CTA + TEHP + D2EHPA (Cross-section)

Figure 8. Scanning electronic microscopy of various membranes.

is slightly lower than that of TOPO. This can be also related to the difference in viscosity between the two organic phases of $\mathrm{D}_{2} \mathrm{EHPA}$ and TOPO, and probably, to the formation of emulsions in the organic phase of TOPO that would block the active surface of the membrane and prevent the metallic ions to react with TOPO molecules present in the membrane.

\subsection{Influence of the $\mathrm{pH}$ of the Strip Phase}

Extraction and transport of a metal cation by an acidic carrier is governed by the exchange of the metal ion for protons of the carrier. Consequently, counter-transport of protons is the driving force and is achieved by maintaining a suitable $\mathrm{pH}$ difference between the strip and feed solutions. In addition, careful $\mathrm{pH}$ control in the source solution can result in good selectivity as in the case of solvent extraction systems using acidic reagents.

Figure 11 represents the variation of the concentration of lead and cadmium ions in the strip phase versus $\mathrm{pH}$ using $\mathrm{D}_{2}$ EHPA carrier. We demonstrate that a maximum permeability for $\mathrm{Pb}$ (II) and $\mathrm{Cd}(\mathrm{II})$ across a CTA + TEHP + D2EHPA membrane from a source phase to a receiving phase was obtained at $\mathrm{pH} 1-2$.

\section{Conclusions}

A cellulose triacetate (CTA) membrane containing organophosphoric carriers (2-ethylhexyl) phosphoric acid noted (D2EHPA) or trioctyl phosphine oxide noted (TOPO) and 2 - nitrophenyloctyl ether noted (NPOE) or Tris ethylhexyl phosphate (TEHP) noted (TEHP) as a plasticizer has been synthesized. These CTA - plasticizer - Carrier membranes were characterised using chemical techniques as well as Fourier Transform Infra-Red (FTIR), X-ray diffraction (DRX) and SEM analysis. The systems constituted by the mixture of CTA + plasticizers + carriers do not give any diffraction. The morphologies of the CTA + Plasticizer + Carrier membranes (view of Cross-section) show that these membranes present a dense structure. A 
Table 2. peak values and the corresponding radicals in different membranes. $m($ CTA $)=0.2 \mathrm{~g}, v($ TEHP $)=v$ $(\mathrm{NPOE})=0.2 \mathrm{~mL}$.

\begin{tabular}{|c|c|c|}
\hline Membrane & Peak value $\left(\mathrm{cm}^{-1}\right)$ & Corresponding radical \\
\hline \multirow{6}{*}{ CTA } & $3480-3550$ & $\mathrm{O}-\mathrm{H}$ \\
\hline & 2935 & $\mathrm{C}-\mathrm{H}$ \\
\hline & 1755 & $\mathrm{C}=\mathrm{O}$ \\
\hline & 1526 & $\mathrm{COO}^{-}$ \\
\hline & 1246 & $\mathrm{C}-\mathrm{O}-\mathrm{C}$ asym \\
\hline & 1054 & $\mathrm{C}-\mathrm{O}-\mathrm{C}$ sym \\
\hline \multirow{5}{*}{ TEHP } & 2960 & $\mathrm{C}-\mathrm{H}$ \\
\hline & 1464 & $\mathrm{CH}_{2}$ \\
\hline & 1381 & $\mathrm{CH}_{3}$ \\
\hline & 1285 & $\mathrm{P}=\mathrm{O}$ \\
\hline & 1020 & $\mathrm{P}-\mathrm{O}-\mathrm{C}$ \\
\hline \multirow{3}{*}{ NPOE } & 1534 & $\mathrm{NO}_{2}$ (NPOE) \\
\hline & 1488 & $-\mathrm{CH}_{3}$ (NPOE) \\
\hline & 1325 & $\mathrm{C}-\mathrm{N}$ (NPOE) \\
\hline \multirow{7}{*}{ TAC + TEHP } & 3477 & $\mathrm{O}-\mathrm{H}(\mathrm{TAC})$ \\
\hline & 2913 & $\mathrm{C}-\mathrm{H}$ \\
\hline & 1767 & $\mathrm{C}=\mathrm{O}(\mathrm{TAC})$ \\
\hline & 1370 & $-\mathrm{CH}_{3}(\mathrm{TAC})$ \\
\hline & 1241 & $\mathrm{C}-\mathrm{O}-\mathrm{C}$ asym \\
\hline & 1054 & $\mathrm{C}-\mathrm{O}-\mathrm{C}$ sym \\
\hline & 1034 & $\mathrm{P}-\mathrm{O}-\mathrm{C}$ \\
\hline \multirow{7}{*}{$\mathrm{TAC}+\mathrm{NPOE}$} & 3481 & $\mathrm{O}-\mathrm{H}$ (TAC) \\
\hline & 1755 & $\mathrm{C}=\mathrm{O}(\mathrm{TAC})$ \\
\hline & 1534 & $\mathrm{NO}_{2}(\mathrm{NPOE})$ \\
\hline & 1488 & $-\mathrm{CH}_{3}(\mathrm{NPOE})$ \\
\hline & 1325 & $\mathrm{C}-\mathrm{N}$ (NPOE) \\
\hline & 1169 & $\mathrm{C}-\mathrm{O}-\mathrm{C}$ (NPOE) \\
\hline & 1096 & $\mathrm{C}-\mathrm{O}-\mathrm{C}(\mathrm{TAC})$ \\
\hline
\end{tabular}

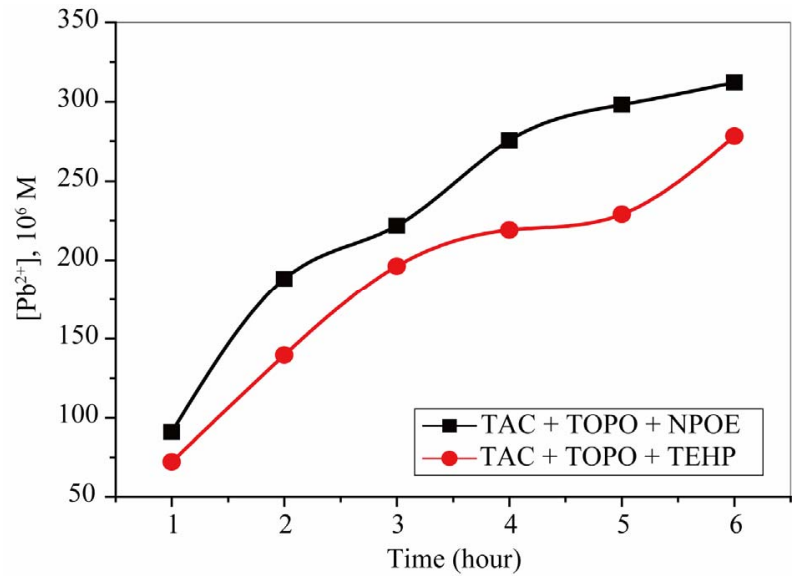

Figure 9. Evolution of the concentration of lead in a strip phase versus time using two plasticizer (NPOE) and (TEHP).

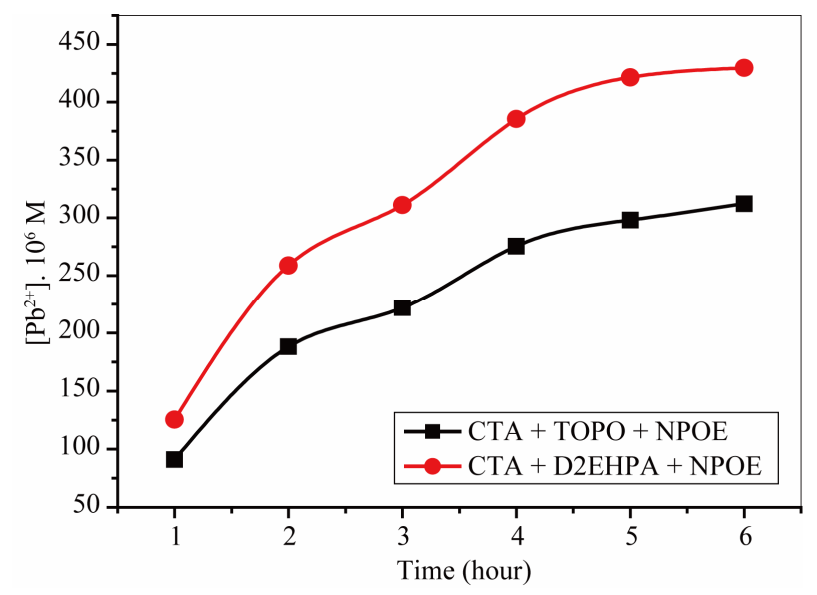

Figure 10. Evolution of the concentration of lead in a strip phase versus time using (CTA + TOPO + NPOE) and (CTA + D2EHPA + NPOE) membranes.

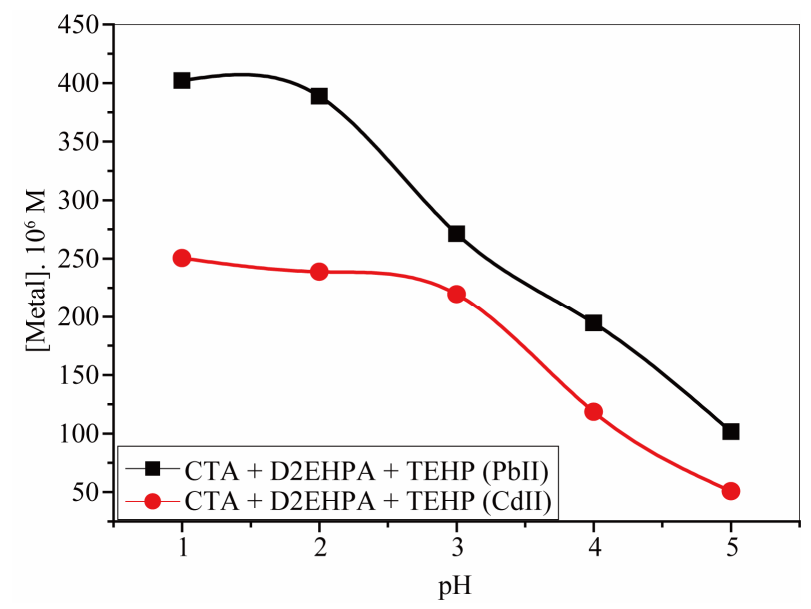

Figure 11. Evolution of the concentration of lead and cadmium in a strip phase versus the $\mathrm{pH}$ of a strip phase using (CTA + D2EHPA + TEHP) membrane. 
study of the transport across a polymer inclusion membrane has shown that the lead or cadmium transport efficiency was increased using D2EHPA as carrier at $\mathrm{pH} 1-2$.

The inclusion of a selective TOPO or D2EHPA in the matrix of a polymer CTA gives rise to stable membranes able to transport ions and to work for a long time. Our results indicate that facilitated transport through plasticized membranes is an attractive and effective way to solve the enduring problem of membrane stability whilst improving the permeability to metal ions.

Further efforts will be directed to the determination of the nature of interactions between polymer and carrier by use of other materials and analysis as well.

\section{REFERENCES}

[1] T. Yamaguchi, K. Nishimura, T. Shinbo and M. Sugiura, "Enantiomer Resolution of Amino Acids by a Polymer-Supported Liquid Membrane Containing a Chiral Crown Ether," Chemistry Letters, Vol. 35, No. 10, 1985, pp. 15491552. doi:10.1246/cl.1985.1549

[2] T. Shinbo, T. Yamaguchi, H. Yanagishita, K. Sakaki, D. Kitamoto and M. Sugiura, "Supported Liquid Membranes for Enantioselective Transport of Amino Acid Mediated by Chiral Crown Ether-Effect of Membrane Solvent on Transport Rate and Membrane Stability," Journal of Membrane Science, Vol. 84, No. 3, October 1993, pp. 241-248. doi:10.1016/0376-7388(93)80019-T

[3] P. Scovazzo, J. Kieft, D. A. Finan, C. Koval, D. DuBois and R. Noble, "Gas Separations Using Non-Hexafluorophosphate [PF6]-Anion Supported Ionic Liquid Membranes," Journal of Membrane Science, Vol. 238, No. 1-2, July 2004, pp. 57-63. doi:10.1016/j.memsci.2004.02.033

[4] A. Figoli, W. F. C. Sager and M. H. V. Mulder, "Facilitated Oxygen Transport in Liquid Membranes: Review and New Concepts," Journal of Membrane Science, Vol. 181, No 1, January 2001, pp. 97-110. doi:10.1016/S0376-7388(00)00508-1

[5] M. Teramoto, N. Takeuchi, T. Maki and H. Matsuyama, "Gas Separation by Liquid Membrane Accompanied by Permeation of Membrane Liquid through Membrane Physical Transport," Separation and Purification Technology, Vol. 24, No 1-2, June 2001, pp. 101-112. doi:10.1016/S1383-5866(00)00216-1

[6] M. Teramoto, S. S. Fu, K. Takatani, N. Ohnishi, T. Maki, T. Fukui and K. Arai, "Treatment of Simulated Low Level Radioactive Wastewater by Supported Liquid Membranes: Uphill Transport of Ce(III) Using CMPO as Carrier," Separation and Purification Technology, Vol. 18, No. 1-3, January 2000, pp. 57-69.

[7] L. A. J. Chrisstoffels, F. de Jong, D. N. Reinhoudt, S. Sivelli, L. Gazzola, A. Casnati and R. Ungaro, "Facilitated Transport of Hydrophilic Salts by Mixtures of Anion and Cation Carriers and by Ditopic Carriers," Journal of the American Chemical Society, Vol. 121, No. 43, November 1999, pp. 10142-10151.

\section{doi:10.1021/ja991588g}

[8] R. A. Bartsch and J. Way, "Chemical Separation with Liquid Membranes," ACS Symposium Series 642, Washington DC, 5 May 1996, pp. 575-579.

[9] J. S. Gardner, J. O. Walker and J. D. Lamb, "Permeability and Durability Effects of Cellulose Polymer Variation in Polymer Inclusion Membranes," Journal of Membrane Science, Vol. 229, No. 1-2, February 2004, pp. 87-93. doi:10.1016/j.memsci.2003.09.017

[10] O. Arous, H. Kerdjoudj and P. Seta, "Comparison of Carrier-Facilitated Silver (i) and Copper (ii) Ions Transport Mechanisms in a Supported Liquid Membrane and in a Plasticized Cellulose Triacetate Membrane," Journal of Membrane Science, Vol. 241, No 2, October 2004, pp. 177-185. doi:10.1016/j.memsci.2004.04.024

[11] M.-F. Paugam and J. Buffle, "Comparison of CarrierFacilitated Copper(II) Ion Transport Mechanisms in a Supported Liquid Membrane and in a Plasticized Cellulose Triacetate Membrane," Journal of Membrane Science, Vol. 147, No. 2, September 1998, pp. 207-215. doi:10.1016/S0376-7388(98)00102-1

[12] L. A. J. Chrisstoffels, F. de Jong and D. N. Reinhoudt, "Mechanic Studies of Carrier-Mediated Transport through Supported Liquid Membranes," In: R. A. Bartsch and J. D. Way, Eds., Chemical Separations with Liquid Membranes, American Chemical Society, Washington DC, 1996, pp. 18-56.

[13] A. J. Schow, R. T. Peterson and J. D. Lamb, "Polymer Inclusion Membranes Containing Macrocyclic Carriers for Use in Cation Separations," Journal of Membrane Science, Vol. 111, No. 2, March 1996, pp. 291-295. doi:10.1016/0376-7388(95)00295-2

[14] J. D. Lamb and A. Y. Nazarenko, "Selective Metal Ion Sorption and Transport Using Polymer Inclusion Membranes Containing Dicyclohexano-18-Crown-6," Separation Science and Technology, Vol. 32, No 17, November 1997, pp. 2749-2764. doi:10.1080/01496399708002220

[15] G. Arena, A. Contino, A. Magri, D. Sciotto and J. D. Lamb, "Selective Transport of Cesium and Strontium Ions through Polymer Inclusion Membranes Containing Calixarenes as Carriers," Supramolecular Chemistry, Vol. 10, No. 2, February 1998, pp. 5-15. doi: $10.1080 / 10610279808054978$

[16] J. D. Lamb, A. Y. Nazarenko, J. Uenishi and H. Tsukube, "Silver(I) Ion Selective Transport across Polymer Inclusion Membranes Containing New Pyridino- and Bipyridino-Podands," Analytica Chimica Acta, Vol. 373, No. 23, November 1998, pp. 167-173.

[17] S. C. Lee, J. D. Lamb, M. H. Cho, C. H. Rhee and J. S. Kim, "A Lipophilic Acyclic Polyether Dicarboxylic Acid as $\mathrm{Pb} 2+$ Carrier in Polymer Inclusion and Bulk Liquid Membranes," Separation Science and Technology, Vol. 35, No 5, March 2000, pp. 767-778. doi:10.1081/SS-100100190

[18] T. T. C. Trang, N. T. Nhung and T. Kobayashi, "Fabrication and Characterization of Pulp/Chitosan Composite 
Membranes Crosslinked with 3-Methylglutaric Anhydride for Pervaporation of Ethanol/Water Mixture," Materials Sciences and Applications, Vol. 3, No 2, February 2011, pp. 110-118.

[19] T. Uragami, I. Sumida, T. Miyata, T. Shiraiwa, H. Tamura and T. Yajima, "Pervaporation Characteristics in Removal of Benzene from Water through Polystyrene/ Poly(Dimethylsiloxane) IPN Membranes," Materials Sciences and Applications, Vol. 2, No. 3, February 2011, pp. 169-179. doi:10.4236/msa.2011.23021

[20] R. T. Peterson and J. D. Lamb, "Chemical Separations with Liquid Membranes,” In: R. A. Bartsch and J. D. Way, Eds., ACS Symposium Series 642, American Chemical Society, Washington DC, 1996, pp. 57-74.

[21] J. C. Aguilar, M. Sánchez-Castellanos, E. R. de S. Miguel and J. de Gyves, "Cd(II) and $\mathrm{Pb}(\mathrm{II})$ Extraction and Transport Modeling in SLM and PIM Systems Using Kelex 100 as Carrier," Journal of Membrane Science, Vol. 190, No. 1, August 2001, pp. 107-118. doi:10.1016/S0376-7388(01)00433-1

[22] N. Bayou, O. Arous, M. Amara and H. Kerdjoudj, "Elaboration and Characterisation of a Plasticized Cellulose Triacetate Membrane Containing Trioctylphosphine Oxyde (TOPO): Application to the Transport of Uranium and Molybdenum Ions," Comptes Rendus Chimie, Vol. 13, No. 11, April 2010, pp. 1370-1376. doi:10.1016/j.crci.2010.04.015

[23] O. Arous, M. Amara and H. Kerdjoudj, "Selective Transport of Metal Ions Using Polymer Inclusion Membranes Containing Crown-Ether and Cryptands," The Arabian Journal for Science and Engineering, Vol. 35, No. 2A, July 2010, pp. 79-93.

[24] O. Arous, M. Amara, M. Trari, A. Bouguelia and H. Kerdjoudj, "Cadmium (II) and Lead (II) Transport in a Polymer Inclusion Membrane Using Tributyl Phosphate as Mobile Carrier and $\mathrm{CuFeO}_{2}$ as a Polarized Photo Electrode," Journal of Hazardous Materials, Vol. 180, No. 1-3, August 2010, pp. 493-498. doi:10.1016/j.jhazmat.2010.04.057

[25] T. G. Levitska, D. M. Macdonald, J. D. Lamb and B. A. Moyer, "Predication of the Carrier-Mediated Cation Flux through Polymer Inclusion Membranes via Fundamental Thermodynamic Quantities: Complexation Study of Bis (Dodecyloxy)Calix(4) Arene-Crown-6 with Alkali Metal Cations," Physical Chemistry Chemical Physics, Vol. 2, No. 7, April 2000, pp. 1481-1491. doi:10.1039/a908840g

[26] A. Gherrou, H. Kerdjoudj, R. Molinari and P. Seta. "Preparation and Characterization of Polymeric Plasticized Membranes (PPM) Embedding a Crown Ether Carrier Application to Copper Ions Transport," Materials Science and Engineering, Vol. C25, No. 4, June 2005, pp. 436-443. doi:10.1016/j.msec.2004.11.002

[27] A. Gherrou, H. Kerdjoudj, R. Molinari, P. Seta and E. Drioli, "Fixed Sites Plasticized Cellulose Triacetate Membranes Containing Crown Ethers for Silver (I), Copper (II) and Gold (III)," Journal of Membrane Science,
Vol. 228, No. 2, January 2004, pp. 149-157. doi:10.1016/i.memsci.2003.10.003

[28] L. D. Nghiem, P. Mornane, I. D. Potter, J. M. Perera, R. W. Cattrall and S. D. Kolev, "Extraction and Transport of Metal Ions and Small Organic Compounds Using Polymer Inclusion Membranes (PIMs)," Journal of Membrane Science, Vol. 281, No. 1-2, September 2006, pp. 7-41. doi:10.1016/j.memsci.2006.03.035

[29] M. Ulewicz, U. Lesinska, M. Bochenska and W. Walkowiak, "Facilitated Transport of $\mathrm{Zn}(\mathrm{II}), \mathrm{Cd}(\mathrm{II})$ and $\mathrm{Pb}(\mathrm{II})$ Ions through Polymer Inclusion Membranes with Calix[4]-Crown-6 Derivatives," Separation and Purification Technology, Vol. 54, No. 3, May 2007, pp. 299-305. doi:10.1016/j.seppur.2006.09.018

[30] N. Pereira, A. St John, R. W. Cattrall, J. M. Perer and S. D. Kolev, "Influence of the Composition of Polymer Inclusion Membranes on Their Homogeneity and Flexibility," Desalination, Vol. 236, No. 1-3, January 2009, pp. 327-333. doi:10.1016/j.desal.2007.10.083

[31] C. Sgarlata, G. Arena, E. Longo, D. Zhang, Y. Yang and R. A. Bartsch, "Heavy Metal Separation with Polymer Inclusion Membranes," Journal of Membrane Science, Vol. 323, No. 2, October 2008, pp. 444-451. doi:10.1016/j.memsci.2008.07.004

[32] N. Pont, V. Salvado and C. Fontas, "Selective Transport and Removal of Cd from Chloride Solutions by Polymer Inclusion Membranes," Journal of Membrane Science, Vol. 318, No. 1-2, June 2008, pp. 340-345. doi:10.1016/j.memsci.2008.02.057

[33] S. D. Kolev, Y. Babab, R. W. Cattrall, T. Tasaki, N. Pereira, J. M. Perera and G. W. Stevens, "Solid Phase Extraction of Zinc(II) Using a PVC-Based Polymer Inclusion Membrane with Di(2-Ethylhexyl)Phosphoric Acid (D2EHPA) as the Carrier," Talanta, Vol. 78, No 3, May 2009, pp. 795-799.

doi:10.1016/j.talanta.2008.12.047

[34] M. Sugiura, M. Kikkawa and S. Urita, "Carrier-Mediated Transport of Rare Earth Ions through Cellulose Triacetate Membranes," Journal of Membrane Science, Vol. 42, No. 1-2, March 1989, pp. 47-55. doi:10.1016/S0376-7388(00)82364-9

[35] S. Azzoug, O. Arous and H. Kerdjoudj, "Cadmium (II) and Lead (II) Extraction and Transport in Supported Liquid Membrane Using TOPO and D2EHPA as Mobile Carriers," Fresenius Environmental Bulletin, Vol. 18, No. 11, May 2009, pp. 2123-2130.

[36] N. S. Murthy, S. T. Correal and H. Minor, "Structure of the Amorphous Phase in Crystallisable Polymers: Poly (Ethyleneterephtalate)," Macromolecules, Vol. 24, No. 5, September 1991, pp. 1185-1189.

[37] G. Vancso, D. Snetvy and I. Tomka, "Structural Changes during Polystyrene Orientation: A Study of Optical Birefringence and Wide Angle X-Ray Scattering," Journal of Applied Polymer Science, Vol. 42, No. 5, March 1991, pp. 1351-1359. doi:10.1002/app.1991.070420518 